\title{
Dirhenium Coordination Complex Endowed with an Intrinsically Chiral Helical-Shaped Diphosphine Oxide
}

\author{
Elsa Quartapelle Procopio, ${ }^{\dagger}$ Davide Dova, $^{\dagger}$ Silvia Cauteruccio, ${ }^{*}{ }^{\dagger}$ († Alessandra Forni, $^{\ddagger \odot}$ \\ Emanuela Licandro, ${ }^{\dagger}{ }^{\circ}$ and Monica Panigati* ${ }^{\dagger} \dagger, \S(0)$ \\ ${ }^{\dagger}$ Dipartimento di Chimica, Università degli Studi di Milano, Via Golgi 19, I-20133 Milan, Italy \\ ${ }^{\ddagger}$ Istituto di Scienze e Tecnologie Molecolari (ISTM-CNR), Via Golgi 19, I-20133 Milan, Italy \\ ${ }^{\S}$ Istituto per lo Studio delle Macromolecole (ISMAC-CNR), Via E. Bassini 15, I-20133 Milan, Italy
}

Supporting Information

\begin{abstract}
A one-pot, multicomponent strategy was used to synthesize the first example of the dirhenium carbonyl coordination complex 2, in which the two metal atoms are connected through a chiral helical-shaped diphosphine oxide. Thanks to the flexibility of the helix of helicene 1, complex 2 was isolated in quite a good yield as a stable compound. It was characterized by analytical and spectroscopic techniques as well as by single-crystal X-ray analysis, which confirmed the chemical structure and the peculiar architecture of 2 . In addition, computational studies were in agreement with the transitions observed in the experimental UV-vis spectrum, revealing the presence of two bands with maxima at about 520 (metal-to-ligand charge transfer) and $400 \mathrm{~nm}$ (IL).
\end{abstract}

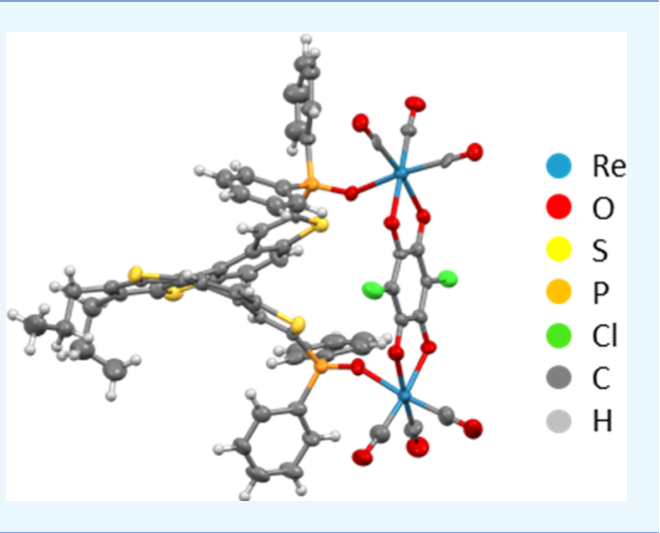

\section{INTRODUCTION}

The helicene-based transition metal complexes are an extremely appealing class of chiral molecules, in which the coordination of metals to $\pi$-helical ligand bearing appropriate coordinating functionalities allows the construction of uncommon chiral architectures. ${ }^{1}$ Indeed, helicenes are ortho-annulated polycyclic aromatic compounds endowed with an inherently chiral $\pi$ conjugated system which have attracted considerable attention because of their unique physicochemical properties and potential applications in different areas of science. ${ }^{2-4}$ On the other hand, reacting $\pi$-helicene scaffolds with metals can significantly modify specific properties, obtaining a structural variety that however retains the defining features of the helical structure. In this context, tetrathia[7]helicenes $(7-\mathrm{TH})$, in which the thiophene rings are fused to alternating benzene rings to form a configurationally stable helix, are emerging as the most promising systems, ${ }^{5}$ also thanks to the reliable functionalization of the terminal thiophene rings of the $7-\mathrm{TH}$ scaffold ${ }^{6-10}$ that allows the introduction of a diversity of functional groups, including those with an efficient coordinating ability (e.g., cyano $^{11}$ and phosphane ${ }^{8,12}$ ). Thus, the $7-\mathrm{TH}$ nitrile derivatives were used as monodentate ligands in the synthesis of the corresponding $\mathrm{Ru}(\mathrm{II})$ and $\mathrm{Fe}(\mathrm{II})$ complexes $^{11}$ that have been shown to be interesting candidates for optoelectronic purposes. More recently, $\mathrm{Rh}(\mathrm{I})$ and $\mathrm{Au}(\mathrm{I})$ complexes based on $7-\mathrm{TH}$ phosphanes $^{8,12}$ or phosphathiahelicenes ${ }^{13,14}$ have been successfully employed in the asymmetric organometallic catalysis. It should be noted that the unique flexibility of the 7-TH skeleton ensures the coordination with different metal centers, affording chelated $\mathrm{Rh}(\mathrm{I})$ complexes $^{8}$ or dinuclear $\mathrm{Au}(\mathrm{I})$ complexes $^{12}$ formed through the coordination of two phosphorus atoms of 7$\mathrm{TH}$ diphosphanes to a rhodium center or two gold centers, respectively. Among several helicene-based coordination complexes reported so far, only one rhenium complex has been described in the literature. ${ }^{15}$ Moreover, enantiopure chiral rhenium complexes are very scarce, and some of them are chiral at the rhenium center, ${ }^{16-21}$ whereas in other cases, a chiral ligand is present. ${ }^{15,22-26}$ The synthesis of some of these complexes is based on metal-direct self-assembly, which affords supramolecular coordination complexes, whose functionalities such as enantioselective recognition, catalysis, and sensing are improved with respect to the organic counterpart. ${ }^{27}$ In this framework, the assembly of $f a c-\operatorname{Re}(\mathrm{CO})_{3}$ units with oxygen anionic donors, or chalcogenide anions, and neutral bridging nitrogen ligand through the direct orthogonal bonding approach represents an example of the synthesis of rhenium-based supramolecular coordination complexes. ${ }^{28-31}$ This one-pot multicomponent approach has also been used for the synthesis of dinuclear rhenium complexes containing the hard ditopic $\mathrm{O}=\mathrm{P}$ donors as the bridging ligand. ${ }^{32-35}$ However, the rhenium-based polynuclear complexes containing $\mathrm{O}=\mathrm{P}$ ligands are very scarce, based on tetraphenyldichalcogenoimidodiphosphinate anions as ligands, ${ }^{34,35}$ and, more recently, flexible alkyl or benzyl diphosphine oxides as neutral ditopic $\mathrm{O}=\mathrm{P}$ ligands

Received: June 8, 2018

Accepted: September 11, 2018

Published: September 24, 2018 
along with a rigid bischelating $\mathrm{O}$ donor (e.g., chloranilic acid and 2,5-dihydroxy-1,4-benzoquinone). ${ }^{32,33}$ In our continuing studies on the synthesis and characterization of organometallic complexes based on the 7-TH derivatives, we focused on the study of the coordination ability of an uncommon and more rigid helical-based phosphine oxide as a neutral ditopic ligand toward dinuclear rhenium complexes containing chloranilic acid as the anionic donor. Herein, we report the first example of a rhenium(I)-based coordination complex in which 7-TH phosphine oxide $( \pm)-\mathbf{1},{ }^{9}$ used as a racemic mixture for this first study, has been selected as a model helical bis $(\mathrm{P}=\mathrm{O})$ donor ligand.

\section{RESULTS AND DISCUSSION}

The dinuclear rhenium(I) complex 2 was synthesized by refluxing $\operatorname{Re}_{2}(\mathrm{CO})_{10}$, the racemic mixture of the $\pi$-helical phosphine oxide $( \pm)-\mathbf{1}$, and chloranilic acid $\left(\mathrm{H}_{2}-\mathrm{CA}\right)$, as anionic donor, in mesitylene for $24 \mathrm{~h}$ (Scheme 1).

Scheme 1. Synthesis of Dinuclear Rhenium(I) Complex 2
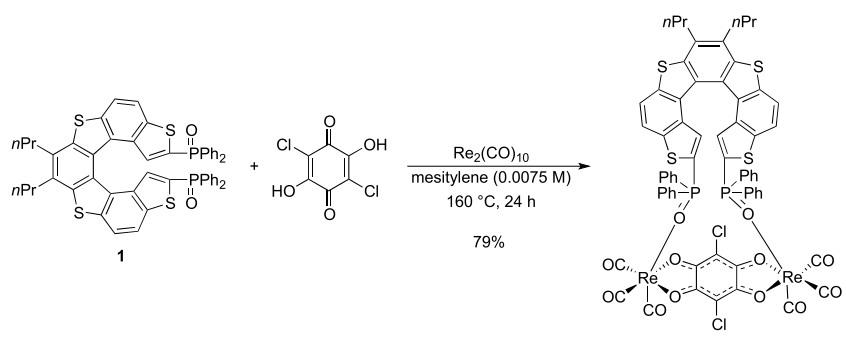

This one-pot procedure involves the oxidative addition of the chloranilate anion to $\left[\mathrm{Re}_{2}(\mathrm{CO})_{10}\right]$, with the reduction of $\mathrm{H}^{+}$to $\mathrm{H}_{2}$, and dissociation of one $\mathrm{CO}$ ligand for each metal center. Then, the further substitution of other two CO groups by the bridging phosphine-oxide ligand $\mathbf{1}$ affords complex 2 . Chromatographic purification of the reaction mixture provided complex 2 in a $79 \%$ yield as an air-stable brown-red solid. It is important to note that 7-TH are known to be configurationally stable heterohelicenes, with a racemization barrier, for example, for the unsubstituted $7-\mathrm{TH}$ of $38.7 \mathrm{kcal} / \mathrm{mol}$ at $227^{\circ} \mathrm{C}$. ${ }^{36}$ Because the temperature of the reaction used for the synthesis of complex 2 is quite lower, this could open the possibility to synthesize the optically active rhenium complex 2 , starting from the corresponding enantiopure phosphine oxide 1 . In fact, the racemization barrier of ligand 1 should be significantly higher than that of the unsubstituted 7-TH because of the presence of two bulky diphenylphosphine oxide groups on the two terminal thienyl rings.

Contrary to other dinuclear rhenium complexes reported by some of us, ${ }^{37}$ complex 2 displayed, in the (CO) region of the infrared (IR) spectrum, only three bands at 2020, 1912, and $1905 \mathrm{~cm}^{-1}$ instead of the typical four-band pattern. This feature has been already observed for the analogous complexes containing the same chloranilate anion as the ancillary ligand, ${ }^{32,33}$ in agreement with the modulation of the position of the carbonyl stretching bands by the nature of the ancillary ligand. The ${ }^{31} \mathrm{P}\left\{{ }^{1} \mathrm{H}\right\}$ NMR spectrum of 2 (Figure $\mathrm{S} 3$ in the Supporting Information) shows only one singlet at $\delta+42.2 \mathrm{ppm}$, indicating a symmetrical bridging coordination of 1 . The symmetrical and dinuclear structure of complex 2 was further confirmed by X-ray analysis. Single crystals suitable for the X-ray structural determination of $\mathbf{2}$ were obtained from the slow diffusion of hexane into toluene solution of complex 2. An Oak Ridge thermal ellipsoid plot (ORTEP) view of the complex is reported in Figure 1.

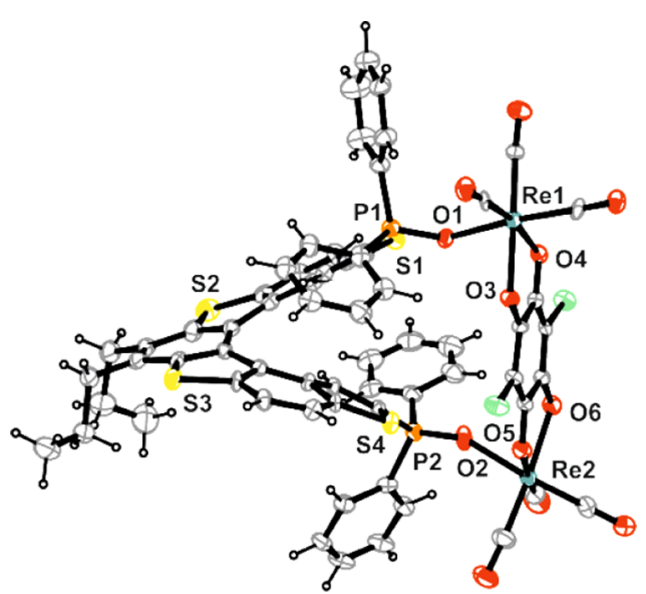

Figure 1. ORTEP view of 2 with the atomic numbering scheme. Ellipsoids are drawn at $20 \%$ probability.

In complex 2, the ditopic 7-TH phosphine oxide ligand coordinates two $\operatorname{Re}(\mathrm{I})$ cations through its $\mathrm{O} 1$ and $\mathrm{O} 2$ oxygen atoms. The chloranilic $\left(\mathrm{CA}^{2-}\right)$ unit acts as the bischelating ancillary ligand bridging the Re cations through its $\mathrm{O} 3, \mathrm{O} 4$ and O5, O6 oxygen atoms. The coordination geometry around each $\mathrm{Re}$ center is completed by three $\mathrm{CO}$ ligands and can be described as distorted octahedron.

Although the atoms of the $\mathrm{C}_{2} \mathrm{O}_{2}$ basal plane show very small tetrahedral distortion, the $\mathrm{Re} 1-\mathrm{O} 1$ and $\mathrm{Re} 2-\mathrm{O} 2$ bonds deviate significantly (by $12.1^{\circ}$ and $15.2^{\circ}$, respectively) from the normal to the $\mathrm{C}_{2} \mathrm{O}_{2}$ plane. Moreover, the $\left\{\left[\operatorname{Re}(\mathrm{CO})_{3}\right](\mu\right.$-CA $)[\mathrm{Re}-$ $\left.\left.(\mathrm{CO})_{3}\right]\right\}$ unit deviates from planarity toward a boatlike conformation, with Re1 and Re2 placed at $0.18(1)$ and 0.39 (1) $\AA$, respectively, from the least-squares plane through the $\mathrm{CA}^{2-}$ ligand. Such distortions are to be related to the geometrical constraint imposed by the 7-TH ligand, as confirmed by comparison with the analogous dinuclear $\operatorname{Re}(\mathrm{I})$ complexes bearing the $\mathrm{O}=\mathrm{P}\left(\mathrm{CH}_{2}\right)_{n} \mathrm{P}=\mathrm{O}\left(n=3^{32}\right.$ and $\left.4^{33}\right)$ ditopic ligands in place of 1 . The distance between the Re cations observed in 2, 8.059(11) $\AA$, is slightly shorter than that reported for the complex with the butyl bridge, $8.08 \AA{ }^{33}$ but significantly longer than that of the complex with the propyl bridge, $7.84 \AA^{32}$ Although in the former complex the $\left\{\left[\operatorname{Re}(\mathrm{CO})_{3}\right](\mu-\mathrm{CA})\left[\operatorname{Re}(\mathrm{CO})_{3}\right]\right\}$ unit is almost planar, in the latter, it assumes a boatlike conformation similar to that observed in 2 but with the Re ions further away from the $\mathrm{CA}^{2-}$ plane. On the other side, the 7-TH ligand is as well expected to undergo a slight distortion after coordination to the metal centers. This is supported by the comparison of the P1... P2 distance in 2, 6.609(6) $\AA$, with that of the previously reported 7-TH phosphonate derivative bearing two EtO groups at the phosphorous atoms in place of the two phenyl groups, ${ }^{8}$ measuring $5.879 \AA$. These results further demonstrate the peculiar flexible nature of the helical system of 7-TH.

The absorption spectra of complex 2 and of the 7-TH ligand 1, recorded in a diluted, air-equilibrated dichloromethane solution at room temperature, are shown in Figure 2.

The absorption spectrum of $\mathbf{2}$ shows two main absorption features. The broad and structureless low-energy absorption band at $514 \mathrm{~nm}\left(\mathrm{ca} .1 .25 \times 10^{4} \mathrm{M}^{-1} \mathrm{~cm}^{-1}\right)$ has been attributed to 


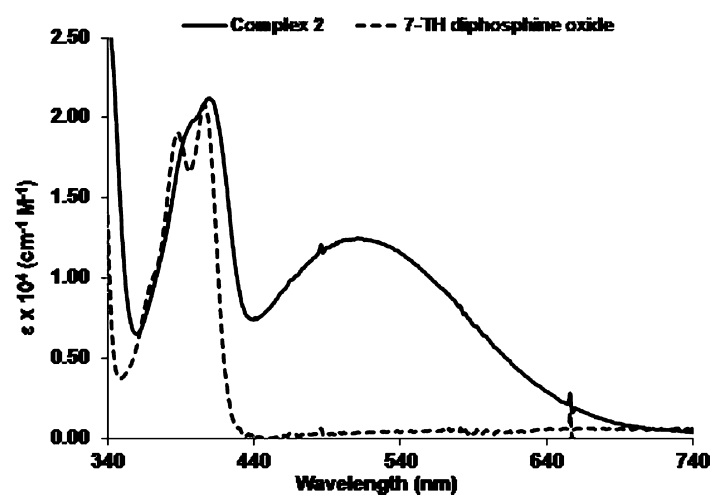

Figure 2. UV-vis absorption spectra of the 7-TH ligand 1 (the dashed line) and of the dinuclear complex 2 (the continuous line) in airequilibrated $\mathrm{CH}_{2} \mathrm{Cl}_{2}$ at $298 \mathrm{~K}$.

the metal-to-ligand $\mathrm{d}(\mathrm{Re}) \rightarrow \pi^{*}\left(\mathrm{CA}^{2-}\right)$ charge-transfer transition (MLCT). Actually, both the energy and the molar absorption coefficients closely resemble those reported for analogous dinuclear rhenium complexes containing phosphine oxide and the chloranilate anion as the ancillary ligand. ${ }^{32,33}$ The spectrum also shows another absorption band at a higher energy (maximum in the range 390-409 nm), with a slightly higher intensity $\left(\varepsilon\right.$ ca. $\left.2.10 \times 10^{4} \mathrm{M}^{-1} \mathrm{~cm}^{-1}\right)$. This band is very similar to that observed for the 7-TH ligand, and it has been attributed to the spin-allowed $\pi-\pi^{*}$ excitations of the helicene skeleton. In comparison to the 7-TH ligand, this band is only slightly redshifted, confirming that this electronic transition does not involve the metal centers. Moreover, it displays a less pronounced vibronic structure. This feature could be attributed to the less coplanar geometry adopted by the helicene ligand inside the complex. The band assignment has been confirmed by time-dependent density functional theory (TDDFT) calculations on the DFT optimized complex. The computed spectrum of 2 in $\mathrm{CH}_{2} \mathrm{Cl}_{2}$ (see Figure $\mathrm{S} 4$ in the Supporting Information) well reproduces the observed one, revealing the presence of two bands with maxima at about 520 and $400 \mathrm{~nm}$. The former is mainly due to the excitations at $527 \mathrm{~nm}$ (oscillator strength $f=$ $0.52)$ and $480 \mathrm{~nm}(f=0.16)$, corresponding to the highest occupied molecular orbital (HOMO) - 3- lowest unoccupied molecular orbital (LUMO) (82\%) and HOMO - 6-LUMO $(88 \%)$ transitions, respectively, where $\mathrm{HOMO}-3$ is delocalized on the $\left\{\left[\operatorname{Re}(\mathrm{CO})_{3}\right](\mu\right.$-CA $\left.)\left[\operatorname{Re}(\mathrm{CO})_{3}\right]\right\}$ moiety, HOMO -6 mainly on the $\left[\operatorname{Re}(\mathrm{CO})_{3}\right]$ units, and LUMO on the $\mathrm{CA}^{2-}$ moiety. The band at higher energy is determined by excitations at $412(f=0.22)$ and $396 \mathrm{~nm}(f=0.30)$, mainly due to HOMO$\mathrm{LUMO}+1$ (96\%) and HOMO - 1-LUMO + 1 (90\%), respectively, where HOMO, HOMO - 1 , and LUMO +1 are all orbitals delocalized on the 7-TH ligand (see Figure S5 in the Supporting Information for a plot of the molecular orbitals mainly involved in the electronic transitions).

\section{CONCLUSIONS}

In conclusion, we have described the synthesis of the first dinuclear rhenium complex in which the two Re centers are connected by an unusual helical diphosphine oxide. This peculiar coordination architecture is possible thanks to the flexibility of the phosphorus-based helical ligand that, also in this case, is able to exhibit different dihedral angles of the helix depending on the steric demand of the surrounding portion of the molecule. Having successfully demonstrated the formation of complex 2, in view of the potential applications of this procedure to synthesize the enantiopure rhenium complexes based on the 7-TH phosphine oxides, some experiments could be performed to assess the configurational stability of these chiral bis $(\mathrm{P}=\mathrm{O})$ donor ligands.

Noteworthy, the spectroscopic characterization of 2 points out a strong absorption maximum in the red portion of the visible spectrum, in line with that observed for the analogous complexes previously reported. This means that the helical system does not perturb the spectroscopic properties of the complex, and this could open the way to investigate the photophysical and chiroptical properties of the corresponding enantiopure complexes.

\section{EXPERIMENTAL SECTION}

Materials and Methods. All the reagents, including $\operatorname{Re}_{2}(\mathrm{CO})_{10}$ and chloranilic acid $\left(\mathrm{H}_{2}-\mathrm{CA}\right)$, were purchased from Aldrich and used as received. Phosphine oxide ( \pm )-1 was synthesized as previously reported. ${ }^{9}$ All the reactions were performed under an inert $\mathrm{N}_{2}$ atmosphere. All the solvents were deoxygenated and dried using standard methods before use; mesitylene was distilled on $\mathrm{Na}(\mathrm{s})$, whereas $\mathrm{CH}_{2} \mathrm{Cl}_{2}$ on $\mathrm{P}_{2} \mathrm{O}_{5}$. Commercial deuterated solvents were used as received. Column chromatography was performed using Alfa Aesar silica gel 60 (0.032-0.063 mm). ${ }^{1} \mathrm{H},{ }^{13} \mathrm{C}\left\{{ }^{1} \mathrm{H}\right\}$, and ${ }^{31} \mathrm{P}\left\{{ }^{1} \mathrm{H}\right\}$ NMR spectra were recorded on a Bruker DRX-400 $\mathrm{MHz}$ instrument, equipped with a Bruker $5 \mathrm{~mm}$ BBI $\mathrm{Z}$ gradient probe head with a maxima gradient strength of $53.5 \mathrm{G} \mathrm{cm}^{-1}$. Chemical shifts are given as $\delta(\mathrm{ppm})$ relative to the residual protonated solvent resonance ( ${ }^{1} \mathrm{H}: \delta=5.32 \mathrm{ppm},{ }^{13} \mathrm{C}: \delta=53.84 \mathrm{ppm}$ for $\left.\mathrm{CD}_{2} \mathrm{Cl}_{2}\right)$. Multiplicities are given as singlet (s), doublet (d), or multiplet $(\mathrm{m})$. The IR spectra in the solution were acquired on a Bruker Vector 22 FT spectrophotometer. The electronic absorption spectra were recorded on an Agilent model 8543 spectrophotometer at room temperature and using quartz cells with a 1.0 $\mathrm{cm}$ path length.

Synthesis of Complex 2. $\operatorname{Re}_{2}(\mathrm{CO})_{10}(10.0 \mathrm{mg}, 0.0153$ $\mathrm{mmol}$ ), $\mathrm{H}_{2}$-CA (1.6 $\mathrm{mg}, 0.0077 \mathrm{mmol}$ ), and phosphine oxide $( \pm)-1(13.6 \mathrm{mg}, 0.0153 \mathrm{mmol})$ were dissolved in $3 \mathrm{~mL}$ of anhydrous mesitylene and the reaction mixture, which was stirred under reflux for one day, slowly turning dark brown. The solution was then evaporated to dryness under a reduced pressure, and the dark red product was purified through column chromatography (toluene/ethyl acetate $8: 2$ ) yielding $10 \mathrm{mg}$ $(0.0061 \mathrm{mmol})$ of microcrystalline powder (yield 79\%). IR $\left(\mathrm{CH}_{2} \mathrm{Cl}_{2}\right)(\mathrm{CO}): 2020(\mathrm{~s}), 1912(\mathrm{~s})$, and $1905(\mathrm{~s}) \mathrm{cm}^{-1} \cdot{ }^{1} \mathrm{H}$ $\mathrm{NMR}\left(\mathrm{CD}_{2} \mathrm{Cl}_{2}, 300 \mathrm{~K}, 400 \mathrm{MHz}\right): \delta 7.88-7.83$ (m, 4H, Ar-H 7$\mathrm{TH}), 7.59-7.43\left(\mathrm{~m}, 8 \mathrm{H}, \mathrm{Ar}-\mathrm{H}-\mathrm{POPh}_{2}\right), 7.26-7.04(\mathrm{~m}, 12 \mathrm{H}$, $\mathrm{Ar}-\mathrm{H}-\mathrm{POPh}_{2}$ ), 6.59 (d, 2H, J = 9.2 Hz, Th-H 7-TH), 3.15$2.99\left(\mathrm{~m}, 4 \mathrm{H}, \underline{\mathrm{CH}}_{2} \mathrm{CH}_{2} \mathrm{CH}_{3}\right), 1.84-1.72\left(\mathrm{~m}, 4 \mathrm{H}, \mathrm{CH}_{2} \underline{\mathrm{CH}}_{2} \mathrm{CH}_{3}\right)$, $1.10\left(\mathrm{t}, 6 \mathrm{H}, \mathrm{J}=7.24 \mathrm{~Hz}, \mathrm{CH}_{2} \mathrm{CH}_{2} \mathrm{CH}_{3}\right) .{ }^{13} \mathrm{C} \mathrm{NMR}\left(\mathrm{CD}_{2} \mathrm{Cl}_{2}, 300\right.$ $\mathrm{K}, 100 \mathrm{MHz}): \delta 141.5(\mathrm{Cq}), 140.3(\mathrm{Cq}), 136.7(\mathrm{Cq}), 134.4$ (Cq), 133.7 (d, $\left.J_{\mathrm{C}, \mathrm{P}}=11.2 \mathrm{~Hz}, 2 \mathrm{CH}_{\text {ortho }}\right), 131.5$ (2 Cq), 131.2 $\left(\mathrm{d}, J_{\mathrm{C}, \mathrm{P}}=10.5 \mathrm{~Hz}, 2 \mathrm{CH}\right), 130.5(\mathrm{CH}), 129.2\left(\mathrm{~d}, J_{\mathrm{C}, \mathrm{P}}=10.5 \mathrm{~Hz}, 1\right.$ $\mathrm{CH}_{\text {meta }}$ ), 128.7 (d, $J_{\mathrm{C}, \mathrm{P}}=12.0 \mathrm{~Hz}, 2 \mathrm{CH}_{\text {para }}$ ), $126.8(\mathrm{Cq}), 121.8$ $(\mathrm{CH}), 121.0(\mathrm{CH}), 34.2\left(\mathrm{CH}_{2}\right), 23.2\left(\mathrm{CH}_{2}\right), 14.2\left(\mathrm{CH}_{3}\right) .{ }^{31} \mathrm{P}$ NMR ( $\left.\mathrm{CD}_{2} \mathrm{Cl}_{2}, 300 \mathrm{~K}, 161 \mathrm{MHz}\right): \delta 42.2(\mathrm{~s})$. Elemental Anal. Calcd for $\mathrm{C}_{64} \mathrm{H}_{40} \mathrm{Cl}_{2} \mathrm{O}_{12} \mathrm{P}_{2} \mathrm{Re}_{2} \mathrm{~S}_{4}$ : C, 47.03; H, 2.47. Found: C, 47.15; $\mathrm{H}, 2.53$.

Single-Crystal X-ray Diffraction Studies on Complex 2. Very thin dark red single crystals of $\mathbf{2}$ suitable for X-ray diffraction have been obtained by recrystallization from toluene. Repeated recrystallization attempts did not allow to improve the 
quality of the crystals, which was in all cases very poor. The intensity data were collected on a Bruker Smart Apex CCD area detector (Bruker AXS Inc., Madison, WI, US) using the graphite-monochromated Mo $\mathrm{K} \alpha$ radiation $(\lambda=0.71073 \AA$ ). Data reduction was made with SAINT, and the absorption corrections based on multiscan were obtained by SADABS. ${ }^{38}$ The structure was solved by SHELXS- $97^{39}$ and refined on F 2 by full-matrix least-squares using SHELXL-14. ${ }^{40}$ Data collection was performed at low temperature $(120 \mathrm{~K})$ to enhance the diffracted intensities and increase the extent of the observed data. A quite low data/parameters ratio prevented to get a meaningful description of the thermal parameters, and, for this reason, several restraints (DELU and ISOR) have been applied on the heavy atoms of the more disordered groups. Moreover, the large void present in the crystal structure suggests the presence of disordered cocrystallized solvent molecule(s), whose structure, however, could not be determined owing to the low resolution of the X-ray data.

Hydrogen atoms were placed in the calculated positions and included in the refinement as "riding". The $\mathrm{H}$ isotropic thermal parameters were fixed at 1.2 (1.5 for methyl groups) times the equivalent thermal parameter of the atoms to which they are bonded. The program ORTEPIII was used for graphics. ${ }^{41}$ The crystallographic data were deposited with the Cambridge Crystallographic Data Centre under the supplementary publication no. CCDC 1844855 . These data can be obtained free of charge via www.ccdc.cam.ac.uk/conts/retrieving.html (or from CCDC, 12 Union Road, Cambridge CB2 1EZ, UK; fax: +44-1223-336-033; e-mail: deposit@ccdc.cam.ac.uk).

Theoretical Studies. Geometry optimization of isolated, gas-phase complex 2 was performed by the Gaussian 16 program package, $^{42}$ using the def2-SVP ${ }^{43,44}$ basis set and the M06 functional, ${ }^{45}$ because of its specific parametrization on organometallic complexes. Rhenium has been treated as a 15-electron system, with relativistic effective core potential taken from the literature. $^{46}$ The X-ray molecular structure of $\mathbf{2}$ was used as the starting point for geometry optimization. The electronic absorption spectrum was computed in dichloromethane on the optimized structure using the same basis set and the PBE0 functional, ${ }^{47}$ owing to its optimal performance in reproducing the absorption spectra of organic ${ }^{48}$ and organometallic compounds. ${ }^{49}$ Solvent effects $\left(\mathrm{CH}_{2} \mathrm{Cl}_{2}\right)$ have been taken into account in all calculations by the polarizable continuum model using the integral equation formalism variant. ${ }^{50}$

\section{ASSOCIATED CONTENT}

\section{S Supporting Information}

The Supporting Information is available free of charge on the ACS Publications website at DOI: 10.1021/acsomega.8b01290.

NMR spectra of $\mathbf{2}$ and crystallographic and computational data (PDF)

Crystallographic data (CIF)

\section{AUTHOR INFORMATION}

\section{Corresponding Authors}

*E-mail: silvia.cauteruccio@unimi.it (S.C.).

*E-mail: monica.panigati@unimi.it (M.P.).

\section{ORCID}

Silvia Cauteruccio: 0000-0002-9540-9073

Alessandra Forni: 0000-0002-5020-5544

Emanuela Licandro: 0000-0003-0168-9295

Monica Panigati: 0000-0001-6649-4865

\section{Author Contributions}

This manuscript was written through contributions from all authors. All authors have given approval to the final version of the manuscript.

Notes

The authors declare no competing financial interest.

\section{ACKNOWLEDGMENTS}

The authors thank Dr. Malaichamy Sathiyendiran for the helpful discussion, which stimulated and inspired this work. The use of instrumentation purchased through the Regione LombardiaFondazione Cariplo joint SmartMatLab Project (2013-1766) is gratefully acknowledged.

\section{ABBREVIATIONS}

7-TH, tetrathiahelicene; $\mathrm{H}_{2}-\mathrm{CA}$, chloranilic acid

\section{REFERENCES}

(1) Saleh, N.; Shen, C.; Crassous, J. Helicene-based transition metal complexes: synthesis, properties and applications. Chem. Sci. 2014, 5, $3680-3694$.

(2) (a) Shen, Y.; Chen, C.-F. Helicenes: synthesis and applications. Chem. Rev. 2012, 112, 1463-1535. (b) Chen, C.-F.; Shen, Y. Helicene Chemistry: From Synthesis to Applications, 1st ed.; Springer-Verlag Berlin Heidelberg, 2017; pp 3-272.

(3) (a) Gingras, M. One hundred years of helicene chemistry. Part 1: non-stereoselective syntheses of carbohelicenes. Chem. Soc. Rev. 2013, 42, 968-1006. (b) Gingras, M.; Félix, G.; Peresutti, R. One hundred years of helicene chemistry. Part 2: stereoselective syntheses and chiral separations of carbohelicenes. Chem. Soc. Rev. 2013, 42, 1007-1050. (c) Gingras, M. One hundred years of helicene chemistry. Part 3: applications and properties of carbohelicenes. Chem. Soc. Rev. 2013, 42, $1051-1095$.

(4) Hoffmann, N. Photochemical reactions applied to the synthesis of helicenes and helicene-like compounds. J. Photochem. Photobiol., C 2014, 19, 1-19.

(5) Licandro, E.; Cauteruccio, S.; Dova, D. Thiahelicenes. Adv. Heterocycl. Chem. 2016, 118, 1-46.

(6) Maiorana, S.; Licandro, E.; Rigamonti, C.; Ticozzelli, M.; Monteforte, M.; Baldoli, C.; Giannini, C. Synthesis and functionalization of novel tetrathia[7]helicenes as new push-pull systems. Synthesis 2006, 3670-3678.

(7) Maiorana, S.; Rigamonti, C.; Ticozzelli, M. T.; Bossi, A.; Licandro, E.; Giannini, C. Novel substituted tetrathia[7]helicenes by direct functionalization of the helical system or photocyclization of substituted 1,2-(bis-benzodithienyl)ethenes. Heterocycles 2008, 76, $1439-1470$.

(8) Monteforte, M.; Cauteruccio, S.; Maiorana, S.; Benincori, T.; Forni, A.; Raimondi, L.; Graiff, C.; Tiripicchio, A.; Stephenson, G. R.; Licandro, E. Tetrathiaheterohelicene phosphanes as helical-shaped chiral ligands for catalysis. Eur. J. Org. Chem. 2011, 5649-5658.

(9) Cauteruccio, S.; Dova, D.; Benaglia, M.; Genoni, A.; Orlandi, M.; Licandro, E. Synthesis, Characterisation, and Organocatalytic Activity of Chiral Tetrathiahelicene Diphosphine Oxides. Eur. J. Org. Chem. 2014, 2694-2702.

(10) Dova, D.; Cauteruccio, S.; Prager, S.; Dreuw, A.; Graiff, C.; Licandro, E. Chiral thiahelicene-based alkyl phosphine-borane complexes: synthesis, X-ray characterization, and theoretical and experimental investigations of optical properties. J. Org. Chem. 2015, 80, 3921-3928.

(11) Garcia, M. H.; Florindo, P.; Piedade, M. F. M.; Maiorana, S.; Licandro, E. New organometallic $\mathrm{Ru}$ (II) and $\mathrm{Fe}$ (II) complexes with tetrathia-[7]-helicene derivative ligands. Polyhedron 2009, 28, 621629.

(12) Cauteruccio, S.; Loos, A.; Bossi, A.; Blanco Jaimes, M. C.; Dova, D.; Rominger, F.; Prager, S.; Dreuw, A.; Licandro, E.; Hashmi, A. S. K. 
Gold(I) complexes of tetrathiaheterohelicene phosphanes. Inorg. Chem. 2013, 52, 7995-8004.

(13) Aillard, P.; Voituriez, A.; Dova, D.; Cauteruccio, S.; Licandro, E.; Marinetti, A. Phosphathiahelicenes: synthesis and uses in enantioselective gold catalysis. Chem.-Eur. J. 2014, 20, 12373-12376.

(14) Aillard, P.; Dova, D.; Magné, V.; Retailleau, P.; Cauteruccio, S.; Licandro, E.; Voituriez, A.; Marinetti, A. The synthesis of substituted phosphathiahelicenes via regioselective bromination of a preformed helical scaffold: a new approach to modular ligands for enantioselective gold-catalysis. Chem. Commun. 2016, 52, 10984-10987.

(15) Saleh, N.; Srebro, M.; Reynaldo, T.; Vanthuyne, N.; Toupet, L.; Chang, V. Y.; Muller, G.; Williams, J. A. G.; Roussel, C.; Autschbach, J.; Crassous, J. enantio-Enriched CPL-active helicene-bipyridine-rhenium complexes. Chem. Commun. 2015, 51, 3754-3757.

(16) Merrifield, J. H.; Strouse, C. E.; Gladysz, J. A. Synthesis, optical resolution, and absolute configuration of pseudotetrahedral organorhenium complexes (.eta.-C5H5) $\operatorname{Re}(\mathrm{NO})(\mathrm{PPh} 3)(\mathrm{X})$. Organometallics 1982, 1, 1204-1211.

(17) Buhro, W. E.; Wong, A.; Merrifield, J. H.; Lin, G. Y.; Constable, A. C.; Gladysz, J. A. Synthesis and chemistry of chiral rhenium acyls (.eta.-C5H5)Re(NO)(PPh3)(COR). Organometallics 1983, 2, 18521859.

(18) Lassen, P. R.; Guy, L.; Karame, I.; Roisnel, T.; Vanthuyne, N.; Roussel, C.; Cao, X.; Lombardi, R.; Crassous, J.; Freedman, T. B.; Nafie, L. A. Synthesis and vibrational circular dichroism of enantiopure chiral oxorhenium(V) complexes containing the hydrotris(1-pyrazolyl)borate ligand. Inorg. Chem. 2006, 45, 10230-10239.

(19) De Montigny, F.; Guy, L.; Pilet, G.; Vanthuyne, N.; Roussel, C.; Lombardi, R.; Freedman, T. B.; Nafie, L. A.; Crassous, J. Subtle chirality in oxo- and sulfidorhenium(V) complexes. Chem. Commun. 2009, 4841-4843.

(20) Faller, J. W.; Lavoie, A. R. Diastereoselective synthesis and electronic asymmetry of chiral nonracemic rhenium $(\mathrm{V})$ oxo complexes containing the hydrotris(1-pyrazolyl)borate ligand. Organometallics 2000, 19, 3957-3962.

(21) Rybak, W. K.; Skarżyńska, A.; Głowiak, T. Efficient Asymmetry Generation in the Synthesis of Oxo-Rhenium(V) Complex cis[ReOCl2 $\{\mathrm{OCMe} 2 \mathrm{CMe} 2 \mathrm{OP}(\mathrm{OCMe} 2 \mathrm{CMe} 2 \mathrm{O})\} \mathrm{py}]$. Angew. Chem. Int. Ed. 2003, 42, 1725-1727.

(22) Chen, J. D.; Cotton, F. A. The first structurally characterized chiral rhenium complex containing a metal-metal quadruple bond. Syntheses, structure, and spectra of .beta.-Re2Cl6[(S,S)-isodiop]: an unprecedented rearrangement of the diop ligand. J. Am. Chem. Soc. 1991, 113, 2509-2512.

(23) Álvarez, C. M.; Carrillo, R.; García-Rodríguez, R.; Miguel, D.pHdriven dynamic stereoinduction: epimerization upon dimerization in rhenium(I) complexes. Chem. Commun. 2011, 47, 12765-12767.

(24) Takacs, E.; Escande, A.; Vanthuyne, N.; Roussel, C.; Lescop, C.; Guinard, E.; Latouche, C.; Boucekkine, A.; Crassous, J.; Réau, R.; Hissler, M. Rhenium complexes bearing phosphole-pyridine chelates: simple molecules with large chiroptical properties. Chem. Commun. 2012, 48, 6705-6707.

(25) Liu, C.; Si, Y.; Shi, S.; Yang, G.; Pan, X. Understanding the photophysical properties of chiral dinuclear $\operatorname{Re}(\mathrm{I})$ complexes and the role of Re(I) in their complexes. Dalton Trans. 2016, 45, 7285-7293.

(26) Lee, S. J.; Lin, W. A chiral molecular square with metallo-corners for enantioselective sensing. J. Am. Chem. Soc. 2002, 124, 4554-4555.

(27) Lehn, J.-M. Supramolecular Chemistry: Concepts and Perspectives; Wiley-VCH: Weinheim, 1995.

(28) Veronese, L.; Quartapelle Procopio, E.; Maggioni, D.; Mercandelli, P.; Panigati, M. Dinuclear rhenium pyridazine complexes containing bridging chalcogenide anions: synthesis, characterization and computational study. New J. Chem. 2017, 41, 11268-11279.

(29) Manimaran, B.; Vanitha, A.; Karthikeyan, M.; Ramakrishna, B.; Mobin, S. M. Self-assembly of selenium-bridged rhenium(I)-based metalla rectangles: synthesis, characterization, and molecular recognition studies. Organometallics 2014, 33, 465-472.

(30) Raimondi, A.; Panigati, M.; Maggioni, D.; D’Alfonso, L.; Mercandelli, P.; Mussini, P.; D’Alfonso, G. Electrochemical, computa- tional, and photophysical characterization of new luminescent dirhenium-pyridazine complexes containing bridging OR or SR anions. Inorg. Chem. 2012, 51, 2966-2975.

(31) Vanitha, A.; Sathiya, P.; Sangilipandi, S.; Mobin, S. M.; Manimaran, B. One-pot synthesis of sulphur bridged dinuclear rhenium metallacycles via addition of S-S bond across Re-Re bond. J. Organomet. Chem. 2010, 695, 1458-1463.

(32) Shankar, B.; Arumugam, R.; Elumalai, P.; Sathiyendiran, M. Rhenium(I)-based monocyclic and bicyclic phosphine oxide-coordinated supramolecular complexes. ACS Omega 2016, 1, 507-517.

(33) Shankar, B.; Elumalai, P.; Shanmugam, R.; Singh, V.; Masram, D. T.; Sathiyendiran, M. New class of phosphine oxide donor-based supramolecular coordination complexes from an in situ phosphine oxidation reaction or phosphine oxide ligands. Inorg. Chem. 2013, 52, 10217-10219.

(34) Rodríguez-Palacios, R.; Reyes-Lezama, M.; Márquez-Pallares, L.; Lemus-Santana, A. A.; Sánchez-Guadarrama, O.; Höpfl, H.; ZúñigaVillarreal, N. Formation of carbonylrhenium cryptates with alkali metal cations: Coordination chemistry studies of $[\mathrm{Ph} 2 \mathrm{P}(\mathrm{E}) \mathrm{NP}(\mathrm{E}) \mathrm{Ph} 2]-$, $\mathrm{E}=\mathrm{O}, \mathrm{S}$, Se towards $\operatorname{ReBr}(\mathrm{CO}) 5$. Polyhedron 2010, 29, 3103-3110.

(35) Lemus-Santana, A. A.; Reyes-Lezama, M.; Zúñiga-Villarreal, N.; Toscano, R. A.; Espinosa-Pérez, G. E. Spontaneous Formation of an Organometallic-Inorganic Dirhenium Carbonyl Cryptate Encapsulating a Sodium Cation. Organometallics 2006, 25, 1857-1860.

(36) Yamada, K.-i.; Nakagawa, H.; Kawazura, H. Thermal racemization of thiaheterohelicenes. Bull. Chem. Soc. Jpn. 1986, 59, 2429-2432.

(37) Panigati, M.; Mauro, M.; Donghi, D.; Mercandelli, P.; Mussini, P.; De Cola, L.; D’Alfonso, G. Luminescent dinuclear rhenium(I) complexes containing bridging 1,2-diazine ligands: photophysical properties and application. Coord. Chem. Rev. 2012, 256, 1621-1643.

(38) Bruker. SMART, SAINT and SADABS; Bruker AXS Inc.: Madison, WI, USA, 1997.

(39) Sheldrick, G. M. A short history of SHELX. Acta Crystallogr., Sect. B: Struct. Sci. 2008, 64, 112-122.

(40) Sheldrick, G. M. Crystal structure refinement with SHELXL. Acta Crystallogr., Sect. B: Struct. Sci., Cryst. Eng. Mater. 2015, 71, 3-8.

(41) Burnett, M. N.; Johnson, C. K. ORTEP-III: Oak Ridge Thermal Ellipsoid Plot Program for Crystal Structure Illustrations; Oak Ridge National Laboratory Report ORNL-6895; Oak Ridge National Laboratory: Oak Ridge, TN, US, 1996.

(42) Frisch, M. J.; Trucks, G. W.; Schlegel, H. B.; Scuseria, G. E.; Robb, M. A.; Cheeseman, J. R.; Scalmani, G.; Barone, V.; Petersson, G. A.; Nakatsuji, H.; Li, X.; Caricato, M.; Marenich, A. V.; Bloino, J.; Janesko, B. G.; Gomperts, R.; Mennucci, B.; Hratchian, H. P.; Ortiz, J. V.; Izmaylov, A. F.; Sonnenberg, J. L.; Williams-Young, D.; Ding, F.; Lipparini, F.; Egidi, F.; Goings, J.; Peng, B.; Petrone, A.; Henderson, T.; Ranasinghe, D.; Zakrzewski, V. G.; Gao, J.; Rega, N.; Zheng, G.; Liang, W.; Hada, M.; Ehara, M.; Toyota, K.; Fukuda, R.; Hasegawa, J.; Ishida, M.; Nakajima, T.; Honda, Y.; Kitao, O.; Nakai, H.; Vreven, T.; Throssell, K.; Montgomery, J. A., Jr.; Peralta, J. E.; Ogliaro, F.; Bearpark, M. J.; Heyd, J. J.; Brothers, E. N.; Kudin, K. N.; Staroverov, V. N.; Keith, T. A.; Kobayashi, R.; Normand, J.; Raghavachari, K.; Rendell, A. P.; Burant, J. C.; Iyengar, S. S.; Tomasi, J.; Cossi, M.; Millam, J. M.; Klene, M.; Adamo, C.; Cammi, R.; Ochterski, J. W.; Martin, R. L.; Morokuma, K.; Farkas, O.; Foresman, J. B.; Fox, D. J. Gaussian 16, Revision A.03; Gaussian, Inc.: Wallingford CT, 2016.

(43) Weigend, F.; Ahlrichs, R. Balanced Basis Sets of Split Valence, Triple Zeta Valence and Quadruple Zeta Valence Quality for H to Rn: Design and Assessment of Accuracy. Phys. Chem. Chem. Phys. 2005, 7, 3297-3305.

(44) Weigend, F. Accurate Coulomb-fitting basis sets for $\mathrm{H}$ to $\mathrm{Rn}$. Phys. Chem. Chem. Phys. 2006, 8, 1057-1065.

(45) Zhao, Y.; Truhlar, D. G. The M06 suite of density functionals for main group thermochemistry, thermochemical kinetics, noncovalent interactions, excited states, and transition elements: two new functionals and systematic testing of four M06-class functionals and 12 other functionals. Theor. Chem. Acc. 2008, 120, 215-241. 
(46) Andrae, D.; Häußermann, U.; Dolg, M.; Stoll, H.; Preuß, H. Energy-adjusted ab initio pseudopotentials for the second and third row transition elements. Theor. Chim. Acta 1990, 77, 123-141.

(47) (a) Perdew, J. P.; Burke, K.; Ernzerhof, M. Generalized Gradient Approximation Made Simple. Phys. Rev. Lett. 1996, 77, 3865-3868.

(b) Adamo, C.; Barone, V. Toward reliable density functional methods without adjustable parameters: The PBE0 model. J. Chem. Phys. 1999, $110,6158-6170$.

(48) Johnson, L. E.; Dalton, L. R.; Robinson, B. H. Optimizing Calculations of Electronic Excitations and Relative Hyperpolarizabilities of Electrooptic Chromophores. Acc. Chem. Res. 2014, 47, 32583265.

(49) Ayache, H.; Hammoutène, D.; Fritsch, E.; Elkechai, A.; Boucekkine, A.; Latouche, C. Comprehensive approach to simulate vibrationally resolved phosphorescence spectra of gold(III) complexes using DFT including temperature effects. Theor. Chem. Acc. 2017, 136, 108.

(50) Tomasi, J.; Mennucci, B.; Cammi, R. Quantum mechanical continuum solvation models. Chem. Rev. 2005, 105, 2999-3094. 